\title{
Interview with Ragni Piene
}

\author{
Ulf A. Persson (Chalmers University of Technology, Göteborg, Sweden)
}

Ragni Piene has a cold and is too tired to go to the department. She graciously invites me to conduct the interview in her home and prepares an omelette for us both for lunch. Through her window, one can see the neighbouring house where she grew up. She has, as they say, returned to her roots. Now, the interview can start; we sit facing each other, with the divided omelette, of which, incidentally, I was given the lion's share, on our plates in front of us, ready to be attacked as well.

Ulf Persson: So let us start from the beginning. How did it all start with mathematics?

Ragni Piene: I always tell people how my father used to sketch, with his ski-pole in the snow, equations for me and my brother to solve when we were spending Easter vacation at Spidsbergseter near the Rondane mountains.

\section{What kind of problems and how old were you?}

It was simple equations in two unknowns. You cannot do anything fancy in the snow with a ski-pole. And I guess I was nine or ten, and my brother was two years older.

\section{Your father was a mathematician?}

Yes and no. He was a mathematical educator; he did not do research in mathematics, if that is what you mean by a mathematician. After completing his degree in Oslo -with excellent grades - he studied abroad: in Copenhagen, Paris and Göttingen, where he followed courses by Hilbert, Courant, Weyl, Herglotz,... He attended the ICM in Oslo in 1936, in Amsterdam in 1954 and in Edinburgh in 1958, and also the Scandinavian mathematics congresses. He was, for many years, an editor of the Norsk Matematisk Tidsskrift and its successor, Nordisk Matematisk Tidsskrift.

\section{So your father was the decisive influence?}

When it comes to mathematics, he was not the only influence. I had very good mathematics teachers. The first was a woman, during my first years at school, and she encouraged me a lot. But it is true my father has been the major influence in my life, much more than my mother. And his influence was not confined to mathematics; it was a general cultural influence, involving art, books, literature, music and politics. My mother was a psychoanalyst, and I was never much interested in psychology. My father's mathematical interest was far more congenial to me.

You were best in the class in mathematics during your school years?

I probably was in the beginning but, at around the age of 13 , compulsory schooling ended in Norway and I entered what was called the "realskole" and then the "gymnasium", modelled, as the traditional school system was in

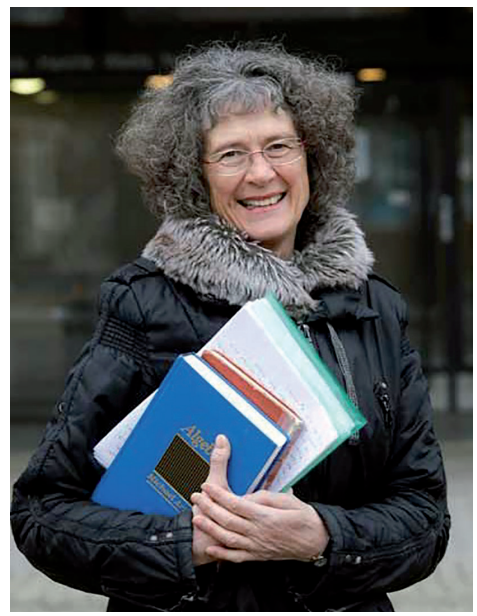

From the flyer "Welcome to UiO", University of Oslo, 2013. Photo: Faculty of Mathematics and Natural Sciences, University of Oslo.

Scandinavia, on the German system. Then, competition was much tougher but, yes, I was always among the very best. I did not get the highest mark in maths in the final exam as I made some trivial mistake. To get the highest mark, you had to be perfect.

What did you like at school and what did you not like? During the first compulsory years at school, schoolwork did not interest me that much; it was sports and handicraft - I liked to knit and sew. It was not until I entered "Katedralskolen" that school became serious. That school, known as "Katta", was an elite school. In order to enrol, you had to have very good grades or - since it was a school run by the state, not the city - come from outside Oslo, which implied that there were children of government and parliament members. In my class, there were the sons of two consecutive prime ministers. I was never particularly studious (that was looked down upon) and I often did my assignments at the very last moment.

I know that attitude well from Swedish schools at the time. To work hard to get good grades was looked down upon; you should get them anyway without effort, otherwise you might as well forget it.

I attended the branch called "reallinjen", which focused on mathematics and physics - in addition to branches in modern languages and classical languages, there was another one in science more attuned to natural sciences such as chemistry and biology.

\footnotetext{
1 Literally the Cathedral school, a common name for higher level schools in Scandinavia, reflecting the close connection between the church and education in traditional times - incidentally, this was the school Niels Henrik Abel attended.
} 
But the latter did not interest you?

No, it did not. And, to be honest, I was not interested in physics either. We had a bad teacher. Now, in retrospect, I regret that I do not know any physics.

\section{What about astronomy?}

That was not a subject at school.

But astronomy is something that appeals to all mathematically inclined children, I would think. It is filled with numbers. One of the first books I read was on astronomy and I soaked in all the vital data of the planets. Also, becoming aware of the large distances filled me with a dreadful sense of vertigo.

That I can very well understand. I, too, was somewhat scared of all that empty space and that horror was somehow connected with the concept of infinity, which got to be very tangible.

After school, you started to study mathematics at university. Surely you had to study other subjects too?

Yes, you had to study two subjects in addition to your major one, which in my case, needless to say, was mathematics.

\section{And physics was not an option.}

Definitely not. Statistics, on the other hand, was a natural option. My father loved statistics but I found I did not. One thing was clear: I did not want to become a teacher. My father would no doubt have loved it. He did, after all, devote his life to the education of teachers but I wanted to get out of the rut - many neighbours and friends of my parents were teachers. So I needed to choose a subject not taught at school and philosophy was one such that appealed to me. I read Kant's critique of reason in German...

...so the German you learned in school came in handy... ....and we did Wittgenstein, reading his Tractatus very carefully (so carefully that we only had time to read part of it).

\section{And what did you think of it?}

I was puzzled and could not quite take it seriously. But what really excited me was logic. We studied Gödel among others. In fact, when I returned to mathematics, logic was my choice. But I was disappointed. It all appeared so contrived to me.

\section{What saved you from logic?}

I was told by a friend to look out for a new course on a topic called algebraic geometry, to be taught by a certain Audun Holme who had just returned from the States. It was rumoured to be very exciting stuff.

\section{What was your next step?}

I wanted to go to Paris; this was clearly where all the action was. And there was a tradition in Norway, especially in Oslo, to go abroad for advanced study, since there were no $\mathrm{PhD}$ programmes at the time.
Karl Egil Aubert, as an example, had gone to Paris for his doctorate and Paris would be the destination of choice for a whole generation of algebraists in Norway. Arnfinn Laudal had been there. So had Dan Laksov and many others. This was the 1960s and there was the excitement of Grothendieck, the Bourbaki seminars, you name it.

\section{So how did you go about it?}

I applied for a French state scholarship. I got a lot of help to do it; local expertise and experience was readily available.

\section{Your advisor was Michel Raynaud - how was it to work with him?}

At that time, at least, he was very formal and forbidding, I guess in the classical French tradition. Appointments to see him in his office had to be made a long time in advance.

\section{Who else did you study with?}

I took courses from Giraud, Demazure and Verdier.

\section{But Raynaud was your main contact?}

I had to present something to him to get my diploma. Not actual research - we read Shafarevich's Lectures on minimal models and birational transformations of two dimensional schemes and then had to exhibit our understanding in front of Raynaud.

\section{A kind of oral.}

I read Shafarevich along with Philippe Lelédy and Renée Elkik - she was really the star, so smart, on top of it all, even generalising results by Michael Artin. Philippe was more on my level.

I recall that she and Boutot visited Harvard for a year or term when I came there in 1971. It must have been shortly thereafter. So how did your French get along?

You keep nagging me about my French all the time. Sure, in the beginning when I was with people, I sat there, saying nothing. The French I took at school had been called oral French but we had had little opportunity to speak French. Our teacher loved songs and we had to learn a lot of French songs.

But you did not burst into song to break out of your silence. You are not the singing type, I presume.

I am definitely not the singing type. I just sat and listened and absorbed and gradually I started making out what they were actually saying and acquiring a vocabulary until I was able to break out of my linguistically imposed shell. I also tried to read French books but I never acquired a proficiency that could be compared to my English. I can sometimes fake it by availing myself of some French mannerism but French is a difficult language, especially when it comes to writing.

Most French cannot write properly themselves... You mean that the rules for written French are made intentionally arcane to preserve a distinction between the educated and the rest. That could well be true. 
What else did you do in Paris? Was mathematics the dominant aspect of your visit or was being in Paris and abroad what most excited you?

I would say both - the one thing required the other. As to other things, I was politically interested, needless to say from the perspective of the far left...

That was very fashionable at the time: sixty-eight and all that - yet another American import starting with the Civil Rights movement, morphing into the Antiwar movement, resulting in student revolts, which spread...

This is probably an accurate analysis. Campus unrest in the States predated May 1968 in Paris. But you should understand that my engagement was not just fashion, as I fear it turned out to be with many others. In Paris, I participated in demonstrations; once, we were trapped inside the Jussieu campus and only those with a Jussieu ID were allowed out. I was terrified of being caught and sent back to Norway, forfeiting my French scholarship. Luckily, it resolved itself at the last minute; I do not recall exactly how.

\section{So you only spent a year in Paris?}

Unfortunately. I would have loved to have had an extension of the scholarship but that was not possible at the time, so I returned to Oslo.

I recall that there was a big conference on algebraic geometry in Oslo that Summer in 1970 but I only found out in retrospect.

You were not informed! Nowadays, that would be unheard of, the way information is spread so effectively.

Maybe too effectively. So, what did you do in Oslo in those years?

I was politically very active; in retrospect, I realise that I was simply being exploited. It took a lot of time and energy, so finishing my Master's thesis (on a topic suggested by Raynaud) took longer than it should.

Eventually, you left Oslo and went to MIT to do a PhD, with Steven Kleiman as your advisor. When you began to work with Kleiman, it meant that you had to start from scratch again?

I would not say "from scratch" but it certainly involved a reorientation from the kind of algebraic geometry I had been doing up to then.

\section{Could you elaborate?}

Already, Hilbert, in his famous lecture in Paris 1900, had addressed the issue of a rigorous foundation for Schubert's enumerative calculus. Enumerative geometry was of no interest at the time for the French school dominated by Grothendieck but a revival of classical geometry took place in the States in the early 1970s and, at a famous meeting in Kalamazoo, Hilbert's problems were considered anew and how to update them. It "fell upon" Kleiman to rework Schubert calculus and enumerative geometry. I was enlisted and my task was to learn about Chern classes and absorb the new intersec-

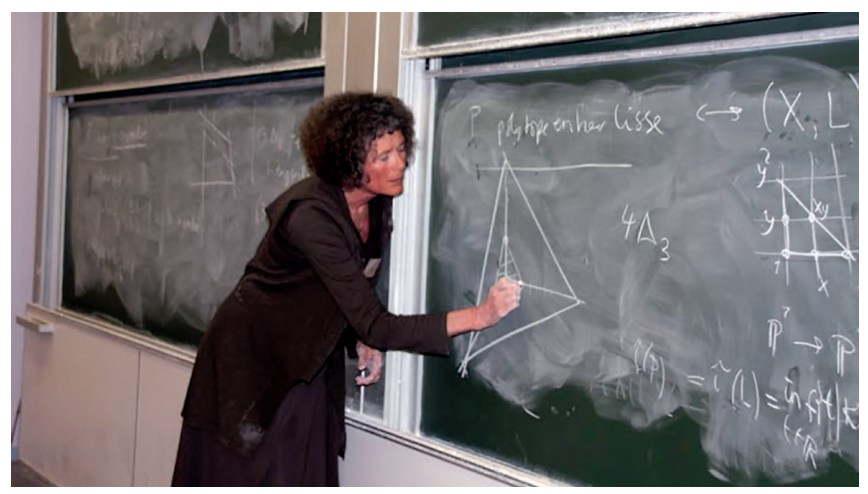

At the conference in honour of Mireille Martin-Deschamps, Université de Versailles, 2010. Photo: Laure Frerejean.

tion theory for singular varieties developed by Fulton and MacPherson.

My work was then cut out for me to study the classical authors and translate them into a modern setting, giving new and rigorous proofs with modern techniques and especially to treat singular varieties.

I recall Mumford reporting how you were climbing up on the giant bust of Mittag-Leffler in the library of that institute in order to get hold of the volumes of Baker hidden above him. Was Baker your favourite author?

I certainly studied him carefully, my eyes being opened up to the riches of late 19th and early 20th century geometry, which had gone out of fashion, as the story you relate indicates.

\section{So how did it go?}

I must admit that I had serious doubts initially. To be honest, this was the first time I had been serious about mathematics; my sojourn in Paris had all been fun in a way and now I was older, more mature and responsible. Did I have what it took? I have always been a good sleeper but now, for the first time, I started being plagued by insomnia. It did pass but, in retrospect, I realise the kind of pressures I was living under. I pulled through though.

I guess according to the oft quoted Nietzschean doctrine that what does not kill you strengthens you. Could you give a taste of what you were doing?

My thesis was about general Plücker formulas for singular varieties. This included a study of polar varieties and their rational equivalence classes. For a nonsingular variety, these polar classes can be expressed in terms of the Chern classes (and vice versa) - by extending the definition of polar varieties to singular varieties, one obtains Chern classes for singular varieties, the so-called ChernMather classes. By taking degrees, I obtained numerical formulas, thus giving rigorous proofs, as well as generalisations, of classical formulas.

\section{And in this vein, you have continued?}

Yes. There have been a lot of bundles of principal parts (or jet bundles), dual varieties, Gauss maps - also in positive characteristics. A main interest over the last few 
years has been joint work with Kleiman on the enumeration of singular curves on surfaces. There have, of course, been other topics, like Hilbert schemes and, more recently, toric varieties, and many other collaborators.

What is your motivation for being a mathematician, except keeping on doing what you have been successful at? Have you ever, for whatever reason, considered applied mathematics?

Actually, many years ago, my mother's friend, who was a professor of medicine, talked to me about biomathematics, which he considered an emerging field. That turned out to be true but I was not particularly interested in biology and did not think I could do anything useful. But I have actually participated in several EU networks on geometric modelling and I will give an invited lecture at the SIAM Conference on Applied Algebraic Geometry in Atlanta this coming August.

But you are a pure mathematician at heart. If you had not done mathematics, you would not have done science?

Definitely not. I would be doing something in the humanities - archaeology, linguistics,...

So, in your opinion, mathematics is a humanistic rather than natural science?

Mathematics is pursued by many different people with very different temperaments. Among them, there certainly are those who have a more engineering type of attitude to mathematics, seeing it in terms of computations, or just as the language of Nature (as famously proclaimed by Galileo).

But your attitude is more that of an artist? You have artists in your family?

On the walls here, you see paintings by my paternal grandfather. As you can tell, he was a professional painter.

Your father did not follow in the footsteps of your grandfather?

In fact, they did not get along very well, I learned later in life. My grandfather was very religious and my father was an avowed atheist.

I think we are digressing. Could you help me get back on track again?

Why don't you ask me about women and mathematics?

That is a good idea. Let us get straight to the heart of it. Do you feel, as a woman, oppressed by your male colleagues?

No. I never felt "oppressed". But there are subtle issues, some coming from always being a minority, and some women mathematicians have had real problems.

So what is the issue? What is the point of forming an association of women mathematicians at all?

Is that not obvious?

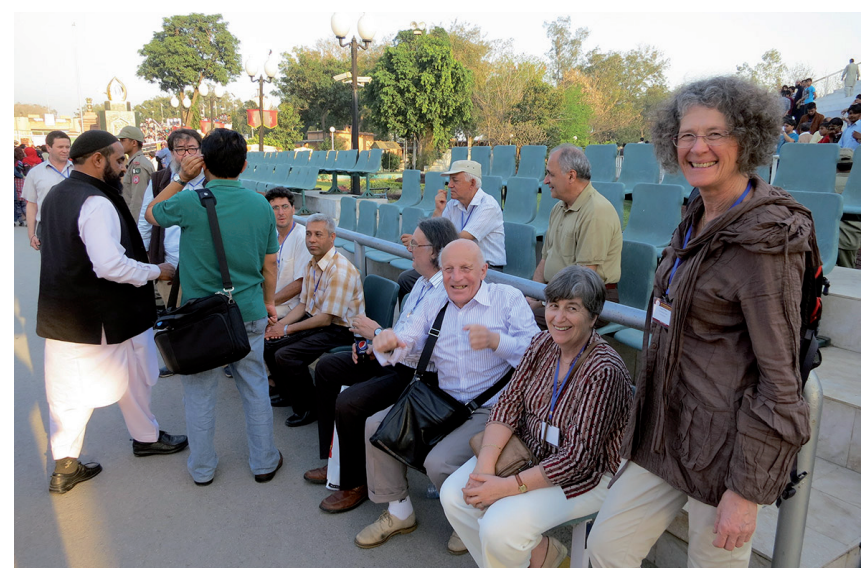

With Pierre Cartier and Aline Bonami at the Wagah Border ceremony, on the occasion of a conference at the Abdul Salam School of Mathematical Sciences in Lahore. Photo: Paul Vaderlind.

If so, could you elaborate? It is not obviously obvious but it may turn out to be.

I will do my best. For one thing, there are very few women in mathematics and I do not think it is a healthy situation. When I came to Paris from Oslo, I was surprised, as well as delighted and encouraged, that there were so many women among my fellow students. Still, during my entire career as a student, I was never once taught a maths course by a woman. Isn't that remarkable?

But you told me that your favourite teacher in mathematics was a woman.

Now you are being silly. This was in elementary school. Women have always been encouraged to become teachers but the issue is not teaching.

\section{I am expected to be provocative.}

That is quite another thing. When I met a few fellow women mathematicians, I felt an instant rapport. Most of them I liked very much; we seemed to have so much in common and we became friends for life.

I have always claimed that those who suffer most from the lack of women in mathematics are male mathematicians, most of whom would gladly exchange many of their male colleagues for women. But I gather it is not the concern for male mathematicians that motivates you. Women mathematicians suffer from the imbalance more than male mathematicians.

But I guess we can agree that the imbalance is due to the choice of women who elect not to become mathematicians not primarily because of the imbalance but because they do not really care that much for mathematics. And one should not force women to become mathematicians if they do not take the initiative themselves.

This is your opinion. I think that more women could have "liked to become mathematicians". Real role models have been missing. Why did you become inspired to become a mathematician?

The short answer is Men of Mathematics by Bell, a book I read in my early teens. 
There, you see! I think Emmy Noether is the only woman included in that book...

You are wrong. You must not have read Bell. The one woman treated at length appears in the chapter on Weierstrass and that is Sofia Kovalevskaya, or Kowalewski as he calls her. Bell ends with Cantor and Poincaré so no modern mathematics. Hilbert was still alive when he wrote...

I guess you are right but my point remains unaffected. When I came to MIT, one of the first books I saw in the bookstore was Women of Mathematics - it had just been published and was, needless to say, much thinner than Bell's.

\section{I see your point. But what exactly do you object to in a male dominated field?}

Needless to say, there exist male mathematicians who resent women, who do not think that women are smart enough to do mathematics or have what it takes.

But I grant you that they tend to be marginal and that I myself have usually been treated with the utmost respect and goodwill.

But goodwill and bending backwards can easily become patronising. These days, when a woman is being honoured in some way or another, there is always the suspicion that it is being done symbolically, not on her own merits but because she is a woman. That is demeaning.

If there would be more of a balance, those problems would not appear. There would, in particular, be no need for "Women in mathematics" and, as you point out, mathematicians are very well equipped to judge performances objectively, unlike in many other academic disciplines. But there is a long way to go. When I came to Paris, as I told you, I was so pleasantly surprised and expected further progress but unfortunately the trend has been broken. That is sad but I think one should not be discouraged. When I have been interviewed by the media, in Norway or abroad, to the extent I have a special message I want to convey, it is simple:

"mathematics + women = true".

I feel I have a duty to be available, to show by personal example. Of course I want to be in control. I recall an incident that angered me a lot. It happened just after I left MIT. A brochure appeared with my face on it and the caption "MIT - a place for women". They did that without consulting me at all. The picture did not identify me, which might be both an extenuating and an aggravating factor but, above all, they should have asked my permission.

But would you have given it if they had asked?

Probably not. MIT was not a place for women at all. In the maths department, there were a few women graduate students but not a single woman on the tenured faculty. To be fair, I should say that the brochure was part of an effort to promote women in science - as was a visiting assistant professorship for a woman. The first to hold this position was Dusa McDuff, which is how I got to meet her.
You have been active in administration, in recent years spectacularly so. How did it all start?

I do not understand what you mean by spectacular?

You did ask before, if you remember, whether I continued doing the same thing. In the mid-1980s, I had a son - this was a very important thing in my life and maybe changed my perspectives somewhat.

Perhaps, as a result, I felt ready to take on responsibilities at the university, acting at one time as Vice-Dean of the Faculty of Mathematics and Natural Sciences.

As to the spectacular aspect, I guess you refer to the General Assembly of the IMU in Shanghai in 2002.

\section{Please continue.}

In 2002, the term of a Scandinavian member of the Executive Committee ended and Erling Størmer, a colleague here in Oslo, thought it would be a good idea that he was replaced by a Scandinavian and suggested Uffe Hagerup, a distinguished Danish mathematician working in operator algebras. But Hagerup declined and my name, I presume as a second choice, was put on the ballot. There was an election at the assembly and I became a member.

I remember I was there and I voted for you, not as a woman or a Scandinavian. You should perhaps point out that this was not just a formality; many names were on the ballot.

Well, I must admit that I found it all very gratifying.

Being elected to the Executive Committee is based on mathematical merit and this is not always compatible with administrative acumen. I figure that you, as a woman of capability and common sense, found yourself a mission there.

It is true that some members are less active and capable than others. Being a very good mathematician does not necessarily mean that you are inept at such tasks. The president during my first term - John Ball - was very efficient and capable and I really enjoyed working with him. I was also lucky that his successor László Lovász was cut from the same cloth.

We forgot to recall that you were the very first woman to become a member of the prestigious Executive Committee; that must have caused a stir.

This is true, and I was interviewed by the magazine New Scientist because of it.

Then, after my first term, there were more women on the committee and, later, Ingrid Daubechies became the first female president ever. I like to think that I, or rather my example, broke ground.

What does it entail working on the Executive Committee? Is it just about arranging the ICM?

Arranging the ICM is the main business, for obvious reasons; it is then when everything comes together. But there are many other issues also. At the general assemblies, many topics are discussed and it is the responsibility of the committee to see that the resolutions are implemented. And then there are many sub-committees and 


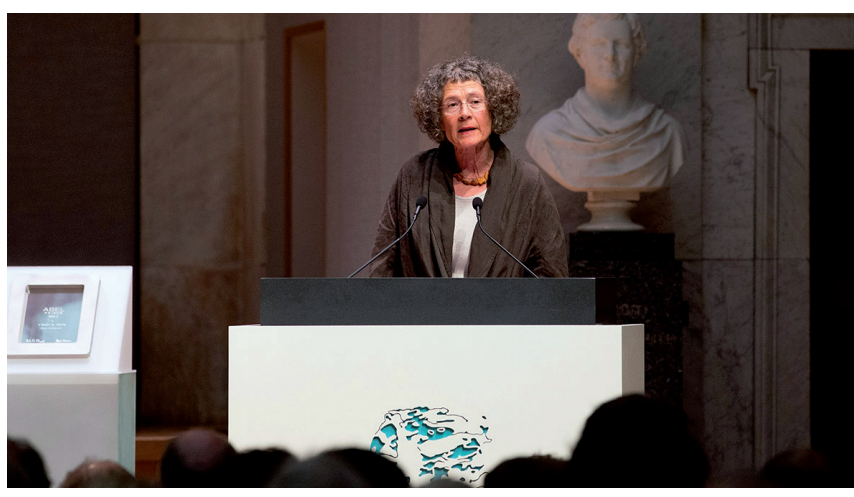

The 2014 Abel Prize ceremony. Photo: The Norwegian Academy of Science and Letters.

commissions - I was involved with the one on mathematics in the developing world.

I got to work with Herb Clemens, who was a pioneer and who has always been very involved in promoting mathematics in the developing world and being attuned to the particular problems that face them.

What is your opinion of the ICMs? Are they too big? Do they fill any function whatsoever?

They are big; that cannot be denied. In the old days, they could still take group pictures of all the participants.

I have a special relation to the ICMs, apart from having been a member of the Executive Committee. The first I "attended" was Edinburgh in 1958 - my father brought the family along. He was a member of the ICMI, the educational commission of the IMU, from 1954 to 1958 and gave an invited talk at the ICM in Amsterdam in 1954 on "School mathematics for Universities and for life" - so, indeed, I have been exposed to it all since childhood.

He also took the family to Moscow in 1966 but sadly he was taken ill and hospitalised - a precursor of what would happen two years later when he died.

I know you think mathematical education has less and less to do with mathematics nowadays...

\section{...or education for that matter.}

You said it. But to return to the ICMs. Having been, for so many years, actively involved with them, I am hardly in a position to dismiss them. I do think they play a very important role...

\section{...apart from giving out the Fields Medals?}

Yes, apart from giving out the Fields Medals. It has to do with the community of mathematicians and the unity of mathematics. The medals have maybe become too important?

\section{But they give mathematics public exposure.}

I think one exaggerates that. True, the Fields Medal has appeared in some movies, notably "Good Will Hunting" but, seriously, how many people outside mathematics do you think know about the Fields Medal? I would think that even people in applied mathematics, non-academics I should add, are not, in general, aware of it.

The first Fields Medals were awarded in Oslo in 1936 , to Ahlfors and Douglas, as you know. Douglas was actu- ally present at the congress but not when the medals were presented. Maybe he overslept or he may not even have been notified and did something else. It was not such a big deal back then. The whole congress was not built around it; it was just a side-issue to provide encouragement to young mathematicians to keep up the good work.

As I recall you putting it once, the Fields Medal bestows greatness, rather than just confirming it, as most other prizes tend to do.

A question that has been raised is whether the names should be announced ahead of the congress.

That would be stupid and against the special aura that surrounds the drama of the medals.

There are leaks of course and sometimes they get it all wrong. But most people are kept in the dark until the very end, so the dramaturgy actually works.

I see that you are getting tired and you want to go back to bed and sleep. I will not keep you much longer. But I cannot refrain from asking you about your involvement with the Abel Prize, especially since I recall that you had some scepticism concerning maths prizes in the past.

I was involved in the Abel Prize from the very beginning and I later chaired the committee for four years. That was very interesting but I obviously cannot disclose any details, let alone secrets, if that is what you are hoping for. Lately, my work has been, together with Helge Holden, to edit and publish, every five years, the books on the Abel Prize laureates. You know those books; you have yourself reviewed them for the EMS Newsletter.

I see that you are really getting very exhausted. I will leave, I promise. Thank you very much for allowing us access to talk to you at such length.

As they say, the pleasure is entirely mine. Good night!

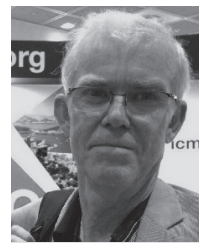

Ulf Persson received his PhD at Harvard in 1975 under David Mumford. His dissertation was entitled "Degenerations of Algebraic Surfaces”. Persson's professional publications have been almost exclusively in algebraic geometry and especially on surfaces. He is inordinately proud of having introduced the notion of the 'geography of surfaces', where the notion of 'geography' has caught on in other contexts. Persson has been based in Sweden since 1979 but did many stints as a visitor to a variety of American universities during the 1980s. In recent years his activities have widened. He founded the Newsletter of the Swedish Mathematical Society during his presidentship and has been its main editor for most of the time since then. He has also been an editor of the EMS Newsletter. He is fond of conducting somewhat idiosyncratic interviews with mathematicians, some of them appearing in this newsletter but the more extreme appearing in the Newsletter of the Swedish Mathematical Society. As is not unusual for people who are aging, he has picked up his youthful interest in philosophy and has published a book and an article on Popper. 